\title{
The effects of process-induced stress on the microstructures and the phase transformation characteristics of sputtered titanium-nickel thin-film shape-memory alloys
}

\author{
Rong Xin Wang ${ }^{1}$, Yitshak Zohar ${ }^{2}$ and Man Wong ${ }^{1}$ \\ ${ }^{1}$ Department of Electrical and Electronic Engineering, The Hong Kong University of Science \\ and Technology, Clear Water Bay, Hong Kong \\ ${ }^{2}$ Department of Mechanical Engineering, The Hong Kong University of Science and \\ Technology, Clear Water Bay, Hong Kong \\ E-mail: eemwong@ee.ust.hk
}

Received 17 May 2001, in final form 5 September 2001

Published 12 October 2001

Online at stacks.iop.org/JMM/11/686

\begin{abstract}
The microstructures and the phase transformation temperatures of sputtered titanium-nickel (TiNi) thin films, both free-standing and attached on different underlying multi-layer substrates, have been studied. Differences in the microstructures, such as the lattice constants and relative concentrations of $\mathrm{TiNi}, \mathrm{Ti}_{2} \mathrm{Ni}$ and $\mathrm{TiNi}_{3}$ phases, have been observed among the free-standing and the attached films, among the films attached on different underlying multi-layers and among the films with different relative orders of ageing and release. Not surprisingly, the corresponding phase transformation temperatures are also different. It is proposed that both process- and substrate-induced stresses affect the microstructures, hence the phase transformation characteristics, of the resulting shape-memory thin films.
\end{abstract}

\section{Introduction}

Because of its large deformation and recovery force, titaniumnickel (TiNi) shape-memory alloys (SMAs) [1] have been actively investigated for both engineering and biomedical applications. While the properties of bulk TiNi are relatively well known, those of thin-film TiNi required for realizing microfabricated systems are not yet adequately understood.

Generally, the properties of thin-film SMAs are significantly different from those of the bulk alloys. One important reason for this is that the shape-memory effect in thin films is influenced not only by the composition of the alloy [1-3], but also by the processing history of the thin films [4-7]. Although a number of microactuators based on TiNi thin films [8-14] have been realized, the factors affecting phase transformations in TiNi thin-film SMAs are still far from being adequately understood.
Two popular techniques of forming thin-film TiNi are sputtering [2-7] and cold-pressing [13, 14]. Compared to sputtering, cold-pressing has been relatively more successful in terms of device applications [13,14]. However, it is less compatible than sputtering with other conventional microfabrication techniques, thus limiting its use to the realization of discrete devices. On the other hand, while sputtering is a conventional microfabrication technique, consistent control of the properties of the resulting thin films has been difficult to achieve. Experience has shown that the properties of sputtered thin films are sensitive not only to processing (sputtering, thermal treatment, etc) conditions, but also to the nature of the underlying substrates on which the films are deposited.

Deposition of TiNi on an underlying substrate including at least a sacrificial layer is inevitable when making actuation devices using microfabrication techniques. The sacrificial 
layer itself may be formed on other thin films that provide suitable electrical and mechanical functions. Though it is well recognized that the choice and composition of the underlying substrate affects the adhesion of TiNi thin films, less is known about their effects, such as those induced by stress or microcontamination, on other properties, such as the microstructures and the phase transformation temperatures, of the resulting thin films.

Recently, the stability under stress of the stoichiometric TiNi phase with respect to other well-documented intermetallics such as $\mathrm{TiNi}_{3}$ and $\mathrm{Ti}_{2} \mathrm{Ni}$ has been considered [15]. It was deduced that when TiNi was heated to a high temperature, the TiNi phase field would shift respectively towards either the $\mathrm{Ni}$-rich $\left(\mathrm{TiNi}+\mathrm{TiNi}_{3}\right)$ or the Ti-rich $\left(\mathrm{TiNi}+\mathrm{Ti}_{2} \mathrm{Ni}\right)$ side of the phase diagram under sufficiently large external tensile or compressive stress. This consideration should be applicable equally well to modelling the effects of process-induced stress on the evolution of the microstructure of sputtered TiNi.

It is the objective of this paper to explore how the nature of the underlying substrate and certain aspects of processing affect the microstructures, hence the resulting phase transformation characteristics, of sputtered TiNi thin films. Besides thin films attached on underlying layers with different compositions, corresponding free-standing thin films have also been studied for comparison. Furthermore, it will be shown that a significant difference in microstructures could be obtained by reversing the relative order of release and ageing, thus demonstrating the strong influence of the presence or absence of an underlying layer during the post-sputtering thermal processing.

\section{Experimental details}

TiNi thin films, $\sim 6 \mu \mathrm{m}$ thick, were deposited on supporting silicon $(\mathrm{Si})$ substrates coated with different multi-layer thin films-(ML-1) $\mathrm{SiO}_{2}(100 \mathrm{~nm}) / \mathrm{Si}_{3} \mathrm{~N}_{4}(100 \mathrm{~nm}) / \mathrm{Cr}(800 \mathrm{~nm})$ or (ML-2) $\mathrm{SiO}_{2}(50 \mathrm{~nm}) / \mathrm{Si}_{3} \mathrm{~N}_{4}(150 \mathrm{~nm}) / \operatorname{poly}-\mathrm{Si}(350 \mathrm{~nm}) / \mathrm{Si}_{x} \mathrm{~N}_{y}$ $(100 \mathrm{~nm}) / \mathrm{Cr}(800 \mathrm{~nm})$ - using magnetron sputtering of a slightly Ni-rich $\mathrm{Ti}_{0.48} \mathrm{Ni}_{0.52}$ target. The base pressure in the radio-frequency (rf) sputtering chamber was $1 \mu$ Torr. $\mathrm{A}$ deposition rate of $45 \mathrm{~nm} \mathrm{~min}{ }^{-1}$ was obtained at a controlled substrate temperature of $300^{\circ} \mathrm{C}$, a process pressure of 3 mTorr, an rf power of $300 \mathrm{~W}$ and a target-to-substrate distance of $\sim 7 \mathrm{~cm}$. Despite the high substrate temperature during sputtering, the as-deposited films were amorphous. This is consistent [16] with the fact that the film composition was slightly Ni-rich, as determined using $\mathrm{x}$-ray fluorescence and energy dispersive $\mathrm{x}$-ray spectroscopy.

The overall stresses on the stacks of thin films associated with ML-1 and ML-2 are expected to be quite different, consistent with the fact that a stoichiometric $\mathrm{Si}_{3} \mathrm{~N}_{4}$ film on $\mathrm{Si}$ is normally in tension and a poly-Si film is normally in compression. The low-stress silicon-rich $\mathrm{Si}_{x} \mathrm{~N}_{y}$ in the present study is compressive. Indeed, prior to $\mathrm{Cr}$ deposition, the room temperature residual stresses in ML-1 and ML-2 are $174 \pm 14 \mathrm{MPa}$ in tension and $109 \pm 13 \mathrm{MPa}$ in compression, respectively.

Some of the TiNi thin films were lifted off the $\mathrm{Cr}$ sacrificial layers and became free-standing. Subsequently, the freestanding and the corresponding films still attached on ML-1

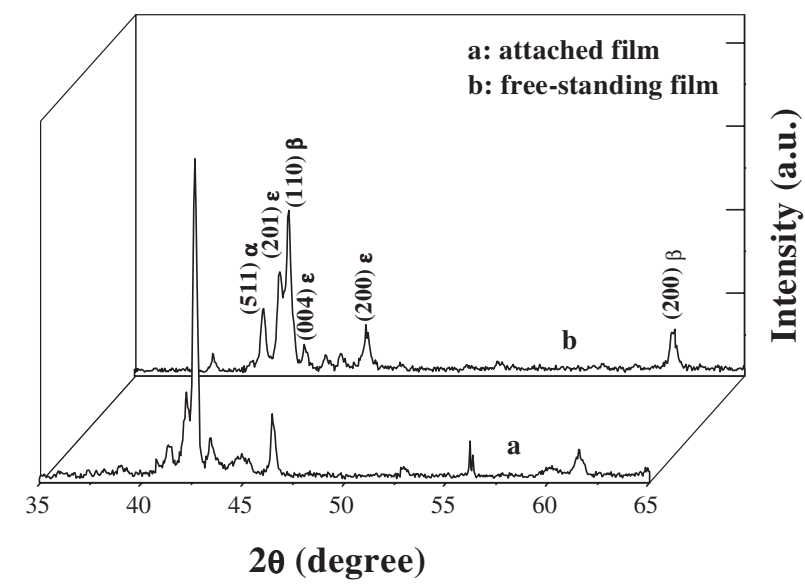

Figure 1. XRD spectra of a free-standing TiNi film and a corresponding film attached on ML-1. Both films were crystallized at $750{ }^{\circ} \mathrm{C}$ for $30 \mathrm{~min}$ and aged at $450{ }^{\circ} \mathrm{C}$ for $100 \mathrm{~h}$.

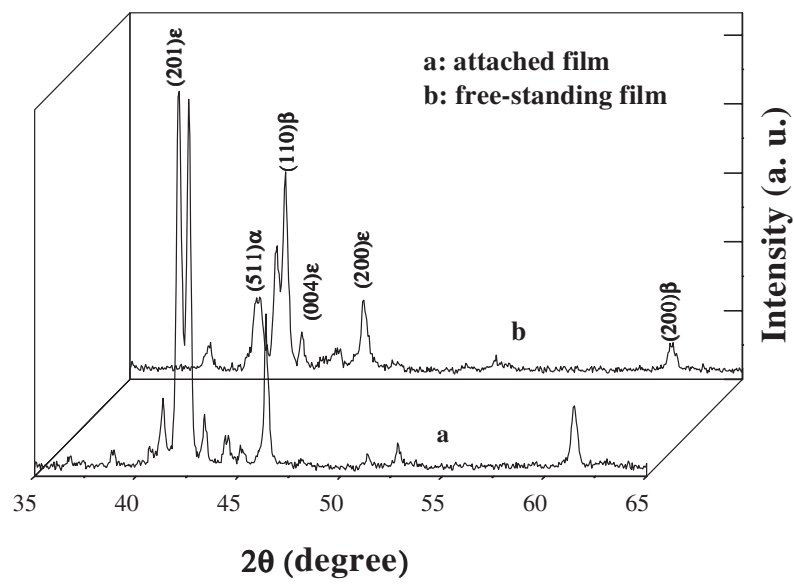

Figure 2. XRD spectra of a free-standing TiNi film and a corresponding film attached on ML-2. Both films were crystallized at $750{ }^{\circ} \mathrm{C}$ for $30 \mathrm{~min}$ and aged at $450{ }^{\circ} \mathrm{C}$ for $100 \mathrm{~h}$.

and ML-2 were crystallized at $750{ }^{\circ} \mathrm{C}$ for $30 \mathrm{~min}$ and aged at $450{ }^{\circ} \mathrm{C}$ for $20 \mathrm{~h}, 50 \mathrm{~h}$ or $100 \mathrm{~h}$ in a $0.1 \mu$ Torr vacuum. The microstructures of the resulting TiNi thin films were determined using X-ray diffraction (XRD) at room temperature. The transformation temperatures of the TiNi thin-film SMAs were measured using differential scanning calorimetry (DSC) with heating and cooling rates of $5{ }^{\circ} \mathrm{C} \mathrm{min}-1$. The surface morphology of the films was studied using scanning electron microscopy (SEM).

\section{Results and discussion}

\subsection{X-ray diffraction}

The XRD spectra of the films attached on ML-1 and ML-2 after $100 \mathrm{~h}$ of ageing are shown in figures 1 and 2, respectively. Spectral peaks corresponding not only to the TiNi phase but also to the $\mathrm{TiNi}_{3}$ and $\mathrm{Ti}_{2} \mathrm{Ni}$ phases can be observed. On the other hand, peaks associated with the $\mathrm{Ti}_{3} \mathrm{Ni}_{4}$ and $\mathrm{Ti}_{2} \mathrm{Ni}_{3}$ phases were too weak to be detected, indicating a relatively much lower presence of these phases in the films. This is not surprising since according to Nishida et al [17], these phases 
Table 1. Lattice constants extracted from the XRD spectra of the films attached on ML-1, ML-2 and their corresponding free-standing films.

\begin{tabular}{llllll}
\hline & & \multicolumn{2}{c}{$\mathrm{TiNi}_{3}(\varepsilon)$ phase } & \multicolumn{1}{c}{$\mathrm{Ti}_{2} \mathrm{Ni}(\alpha)$ phase } & \multicolumn{1}{c}{$\mathrm{TiNi}(\beta)$ phase } \\
& & $a$ & $c$ & $a$ & $a$ \\
\hline ML-1 & Free-standing & $5.118 \pm 0.002$ & $8.35 \pm 0.06$ & $11.357 \pm 0.002$ & $3.009 \pm 0.004$ \\
& Attached & $5.115 \pm 0.002$ & $8.33 \pm 0.03$ & $11.327 \pm 0.003$ & $3.010 \pm 0.008$ \\
ML-2 & Free-standing & $5.109 \pm 0.003$ & $8.32 \pm 0.07$ & $11.325 \pm 0.009$ & $3.009 \pm 0.007$ \\
& Attached & $5.116 \pm 0.001$ & $8.344 \pm 0.007$ & $11.3522 \pm 0.0005$ & $3.013 \pm 0.008$ \\
& Released attached & $5.113 \pm 0.001$ & $8.336 \pm 0.003$ & $11.3433 \pm 0.0008$ & $3.014 \pm 0.009$ \\
\hline
\end{tabular}

are metastable and change into stable $\mathrm{TiNi}_{3}$ precipitates [7] after extended ageing.

Further inspection of figures 1 and 2 reveals that the intensities of TiNi relative to those of $\mathrm{Ti}_{2} \mathrm{Ni}$ and $\mathrm{TiNi}_{3}$ are quite different for the attached films and the corresponding free-standing films detached from the respective substrates, indicating a strong difference in the relative concentrations of the different phases. Furthermore, the relative phase concentrations in the films is also substrate dependent.

Either $\mathrm{Cr}$ contamination or film stress may be the cause of the observed microstructural difference between the films attached on different substrates and between the films attached on and later detached from similar substrates. However, the former could be eliminated as a dominant cause because (a) no $\mathrm{Cr}$ has been detected in the released films using $\mathrm{X}$-ray fluorescence, and (b) the films attached on ML-1 and ML-2, while both exposed to $\mathrm{Cr}$ during the crystallization/ageing heat treatments, exhibited different microstructures. The lack of $\mathrm{Cr}$ penetration into the TiNi film is consistent with the $\mathrm{x}$-ray photo-electron spectroscopic results reported by Roch et al [18]. Therefore, it is more likely that the different mechanical stresses exerted on the TiNi thin film during the crystallization and the ageing process could be the main factor causing the differences among the XRD spectra.

The free-standing films are relatively stress free, but the attached films may experience strong stress due to the structural and thermal expansion coefficient mismatch between the TiNi thin films and the underlying multi-layers. Furthermore, the resulting stress after high-temperature treatment is likely to be different for films attached on different underlying multi-layers with different mechanical and thermal properties.

It is well known that the lattice constants of a crystalline material are stress dependent. Hence it is possible to deduce the nature of the stress by studying changes in the lattice constants. The latter have been estimated by using Bragg's law to analyse shifts of the XRD diffraction peaks. The results are summarized in table 1 . It can be seen that the constants associated with the free-standing films are respectively larger or smaller than those of the corresponding film attached on ML-1 or ML-2. Consequently, the film attached on ML-1 or ML-2 is, respectively, in tension or compression relative to the corresponding free-standing film [19].

When tensile or compressive stress is applied during hightemperature annealing, the TiNi phase field is shown to shift respectively to the $\mathrm{Ni}$-rich $\left(\mathrm{TiNi}+\mathrm{TiNi}_{3}\right)$ or Ti-rich $(\mathrm{TiNi}$ $+\mathrm{Ti}_{2} \mathrm{Ni}$ ) sides of the phase diagram [15]. Consequently, the concentration of the Ni-rich $\mathrm{TiNi}_{3}$ phase should decrease relative to that of the TiNi phase under increasing tensile stress. This is consistent with the observations that: (a) the intensity of the TiNi peak relative to that of the $\mathrm{TiNi}_{3}$ peak is higher for the

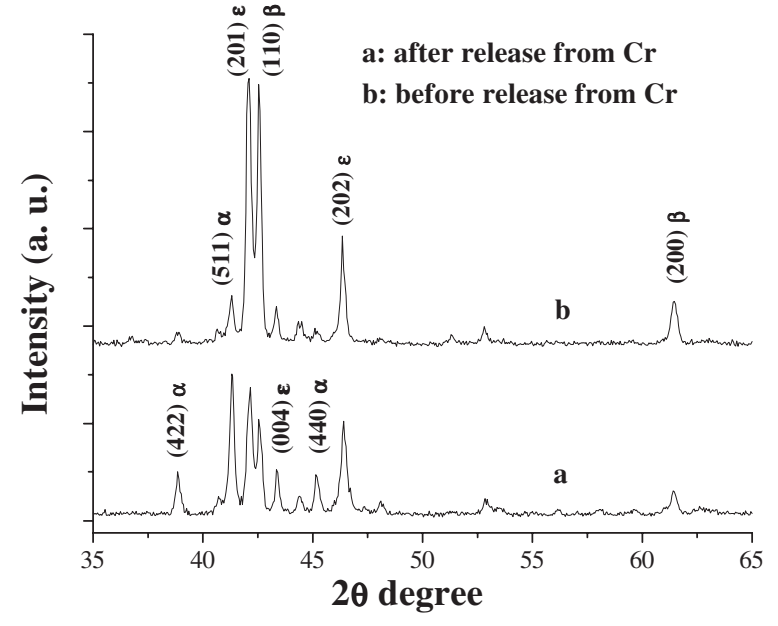

Figure 3. XRD spectra of a TiNi thin film aged for $100 \mathrm{~h}$ while attached on ML-2: (a) after and (b) before being released at room temperature.

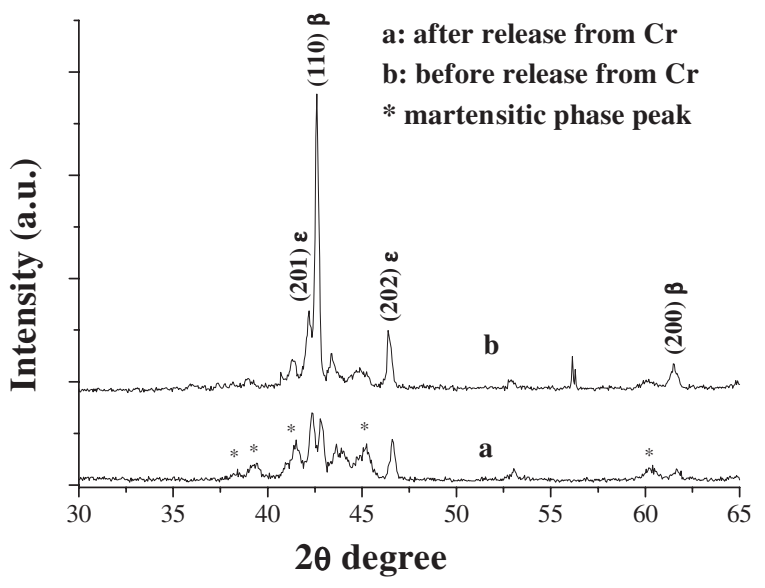

Figure 4. XRD spectra of a TiNi thin film aged for $100 \mathrm{~h}$ while attached on ML-1: (a) after and (b) before being released at room temperature.

tensile film attached on ML-1 than for the corresponding freestanding film (figure 1); and (b) the $\mathrm{TiNi}_{3}$ peak becomes much more prominent in the spectrum of a compressive film attached on ML-2 than in that of the corresponding free-standing film (figure 2).

Stress changes at room temperature were also found to affect the microstructures of TiNi thin films. This is evident from the drastic changes in the XRD spectra obtained before and immediately after the room-temperature release of crystallized/aged TiNi from ML-1 and ML-2. A significant relative increase in the intensity of the $\mathrm{Ti}_{2} \mathrm{Ni}$ peak (figure 3 ) 


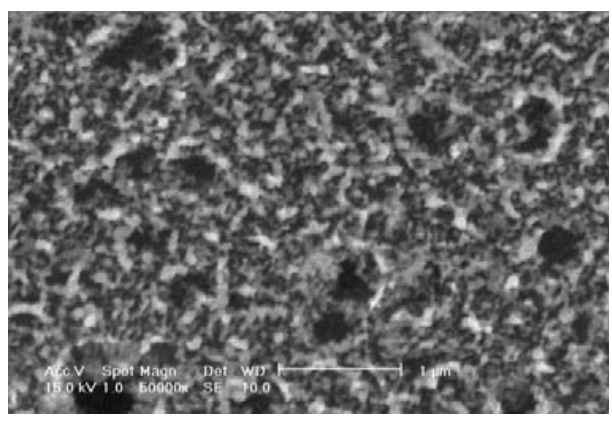

(a)

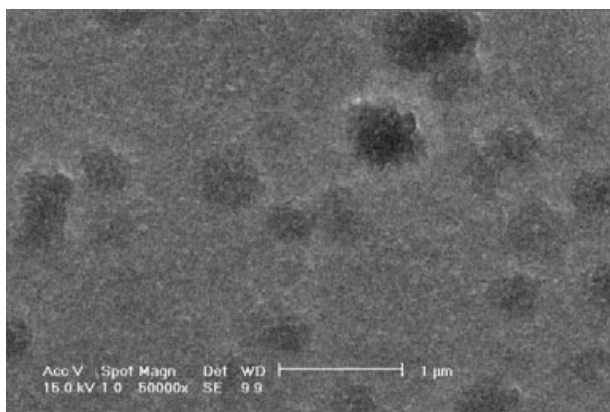

(b)

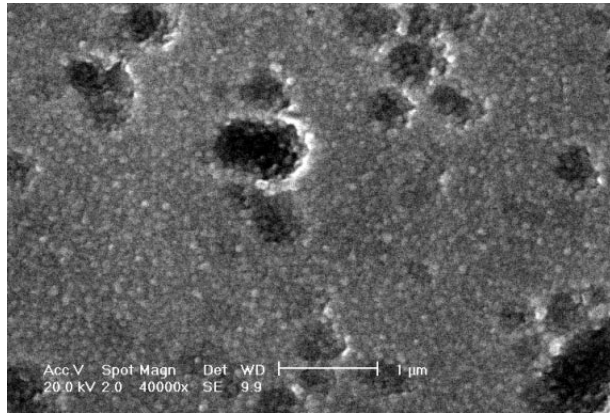

(c)

Figure 5. SEM micrographs of $(a)$ a film detached from ML-2 after $100 \mathrm{~h}$ of ageing, $(b)$ a film detached from ML-2 before crystallization and aged for $100 \mathrm{~h}$ and $(c)$ as-sputtered amorphous film.

can be observed when the compressive film attached on ML-2 is detached. The opposite is not observed when the tensile film attached on ML-1 is detached. Instead, the intensity of the spectral peaks associated with the TiNi austenitic phase decrease and additional peaks associated with the TiNi martensitic phase can be clearly identified. Therefore, a change from the austenitic to the martensitic phase has occurred during the release (figure 4). These results demonstrate unambiguously the dominant role of stress in determining the microstructures of sputtered TiNi film, even at room temperature.

It should be noted that while the lattice constants of a free-standing film detached from ML-2 after the ageing process are smaller than those obtained on a corresponding compressive film still attached on ML-2, they are different from (in fact larger than) those of a free-standing film aged after being detached from ML-2. This is evidence of the dominant role of stress during thermal processing in determining the microstructures of sputtered TiNi films.

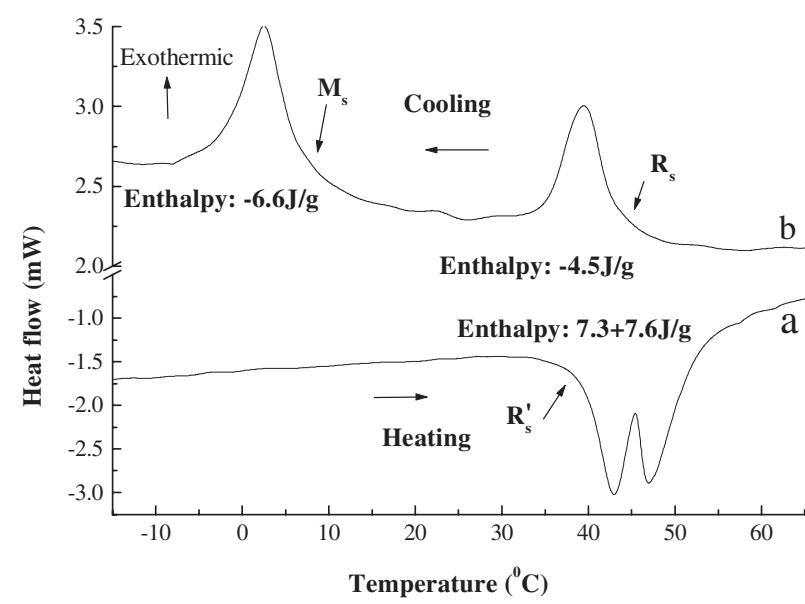

Figure 6. Heating (curve a) and cooling (curve b) DSC curves of TiNi films detached from ML-1 after being crystallized at $750{ }^{\circ} \mathrm{C}$ for $30 \mathrm{~min}$ and aged at $450{ }^{\circ} \mathrm{C}$ for $100 \mathrm{~h}$.

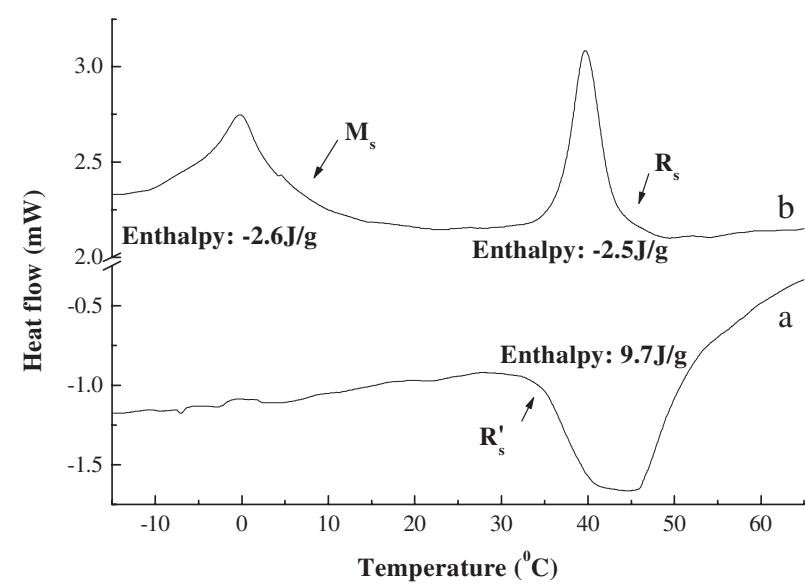

Figure 7. Heating (curve a) and cooling (curve b) DSC curves of TiNi films detached from ML-2 after being crystallized at $750{ }^{\circ} \mathrm{C}$ for $30 \mathrm{~min}$ and aged at $450{ }^{\circ} \mathrm{C}$ for $100 \mathrm{~h}$.

\subsection{Surface morphology}

It is well known that the morphology of a thin film can be affected by its strain/stress state. That this has happened in the case of TiNi thin films can be seen from the SEM micrographs shown in figure 5 . The morphologies of a film detached from ML-2 after $100 \mathrm{~h}$ of ageing (figure 5(a)) and a corresponding film detached from the substrate before being crystallized and aged for $100 \mathrm{~h}$ (figure 5(b)) are different. Compared with that of the as-sputtered amorphous film (figure 5(c)), the surface of a film aged after release is domed but smooth while that of the film released after ageing is rough with pits and islands. This is consistent with the fact that during the ageing process the stress is relieved in the former film while relatively strong stress is present in the latter film. A similar difference in morphology has been observed for the films detached from ML-1 before and after being crystallized and aged.

\subsection{Phase transformation characteristics}

The application of an external stress has been shown to change the austenitic/martensitic phase transformation temperatures 


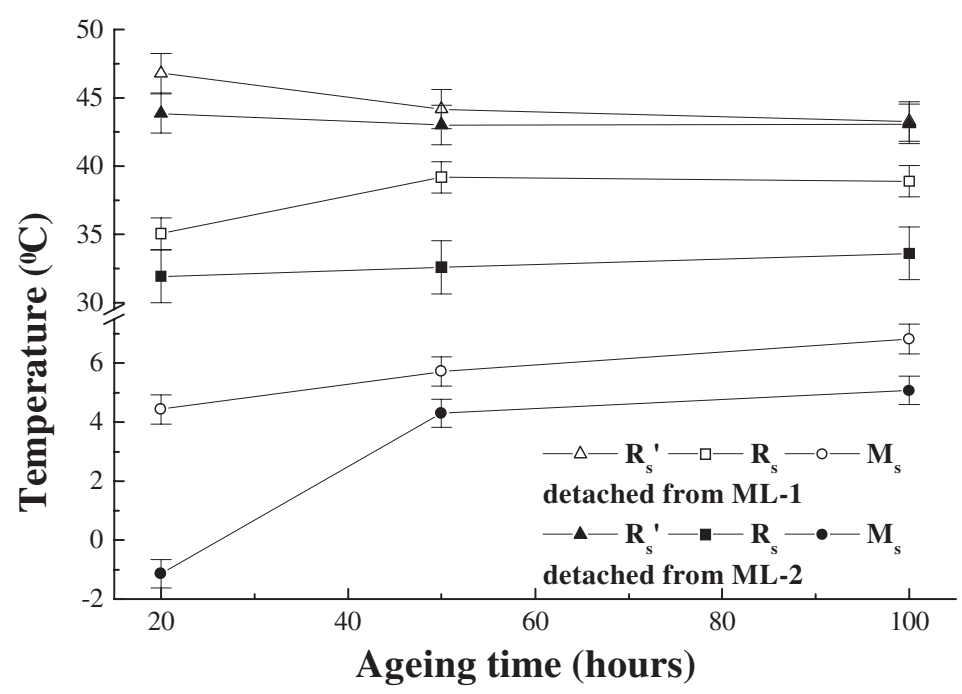

Figure 8. Dependence of the phase transformation temperatures, $R_{\mathrm{s}}^{\prime}, R_{\mathrm{S}}$ and $M_{\mathrm{s}}$, on the ageing time of the films detached from ML-1 and ML-2.

of bulk [20] and thin-film TiNi SMAs [5,7]. The detailed effects of process-induced stress during thermal processing and the relaxation of this stress during release have not been reported previously. However, given the sensitivity of phase transformation kinetics to thin-film microstructures and the dependence of the latter on process-induced stress, it is not surprising that the corresponding phase transformation temperatures of the resulting SMA thin films are dependent on the nature of the underlying material and the history of the thermal processing.

The DSC characteristics of the films detached from ML-1 and ML-2 after $100 \mathrm{~h}$ of ageing are shown in figures 6 and 7 , respectively. While the cooling curves are qualitatively similar, the heating curves are more dissimilar with less overlap of the rhombohedral and austenitic phases observed in the film originally attached on ML-1. Indicated on the figures are the enthalpy values and phase transformation 'start' temperatures. The enthalpy values are significantly larger for the films attached on ML-1 than for those attached on ML-2. From the cooling curves, the rhombohedral $\left(R_{\mathrm{S}}\right)$ and martensitic $\left(M_{\mathrm{S}}\right)$ phase start temperatures for the films detached from ML-1 and ML-2 after ageing are extracted. Similarly from the heating curves, the reverse rhombohedral $\left(R_{\mathrm{s}}^{\prime}\right)$ phase start temperatures are extracted. These are plotted as a function of the ageing time in figure $8 . R_{\mathrm{s}}^{\prime}, R_{\mathrm{S}}$ and $M_{\mathrm{S}}$ can be seen to increase with increasing ageing time [21]. Not surprisingly, since the microstructures of the films detached from ML-1 and ML-2 are different, the phase start temperatures are different. In fact, those originally attached on ML-1 are consistently higher.

\section{Conclusions}

The absence, presence and the nature of the underlying multi-layer substrates have been shown to have important effects on the microstructures and the corresponding phase transformation characteristics of sputtered TiNi SMA thin films. It is also reported that different microstructures can also be obtained by reversing the relative order of ageing and release. Consequently, it is proposed that process- and substrate-induced stress plays a significant role in determining the microstructures, hence the phase transformation characteristics, of the resulting thin films.

\section{Acknowledgments}

The authors would like to acknowledge the generous assistance of their colleagues in the Microelectronics Fabrication Facility and the Materials Characterization and Preparation Facility at the Hong Kong University of Science and Technology. This work was supported by a grant from the Research Grants Council of Hong Kong.

\section{References}

[1] Funakubo H (ed) 1984 Shape Memory Alloys (New York: Gordon and Breach) (translated by J B Kennedy)

[2] Nomura K, Miyazaki S and Takei A 1994 Transformation and deformation behavior of sputter deposited Ti-Ni thin films Trans. Mater. Res. Soc. Jpn. 18B 1049

[3] Ishida A, Takei A and Miyazaki S 1993 Shape memory thin film of Ti-Ni formed by sputtering Thin Solid Films $\mathbf{2 2 8} 210$

[4] Miyazaki S, Nomura K and Ishida A 1995 Shape memory effects associated with the martensitic and R-phase transformation in sputter-deposited $\mathrm{Ti}-\mathrm{Ni}$ thin films J. Physique IV C8 677

[5] Ishida A, Sato M, Takei A, Kase Y and Miyazaki S 1995 Effect of heat treatment on shape memory behavior of Ti-Ni thin films J. Physique IV C8 701

[6] Grummon D S, Li H, Zhao Z and Pence T J 1995 Progress on sputter-deposited thermotractive titanium-nickel films J. Physique IV C8 665

[7] Zhang J, Cai W, Ren X, Otsuka K and Asai M 1999 The nature of reversible change in $M_{s}$ temperature of Ti-Ni alloys with alternating aging Mater. Trans. JIM 401367

[8] Krulevitch P, Lee A P, Ramsey P B, Trevino J C, Hamilton J and Northrup M A 1996 Thin film shape memory alloy micro-actuators J. Microelectromech. Syst. 5270

[9] Takeuchi S and Shimoyama I 1999 Three-dimensional SMA microelectrodes with clipping structure for insect neural recording Proc. Transducers'99 p 464

[10] Ma C C, Wang R X, Sun Q P, Zohar Y and Wong M 2000 Frequency response of TiNi shape memory alloy thin film micro-actuators Proc. IEEE, MEMS'2000 p 370 
[11] Nakamura Y, Nakamura S, Buchaillot L and Fujita H 1997 A three-dimensional shape memory alloy loop actuator Proc. IEEE, MEMS'97 p 262

[12] Benard W L, Kahn H, Heuer A H and Huff M A 1998 Thin-film shape-memory alloy actuated micropumps IEEE J. Microelectromech. Syst. 7245

[13] Kohl M, Skrobanek K D and Miyazaki S 1999 Development of stress-optimised shape memory microvalves Sensors Actuators A 72243

[14] Just E, Kohl M, Pfleging W and Miyazaki S 1999 SMA microgripper with integrated antagonism Proc. Transducers'99 p 1768

[15] Jardine A P 1993 TiNi phase diagram with applied stress Mater. Res. Soc. Symp. Proc. 311131

[16] Seguin J L, Bendahan M, Isalgue A, Esteve-Cano V, Carchano H and Torra V 1999 Low temperature crystallized Ti-rich NiTi shape memory alloy films for microactuators Sensors Actuators A 7465

[17] Nishida M, Wayman C M and Honma T 1986 Precipitation process in near-equiatomic TiNi shape memory alloys Metall. Trans. A 17A 1505

[18] Roch I, Buchaillot L, Wallart X and Collard D 2001 Silicon nitride as an effective protection against oxide of a TiNi thin film in high temperature oxide air environment at atmospheric pressure J. Vac. Sci. Technol. B 19305

[19] Qi B, Kim D, Willamson D L and Trefny J U 1996 Effects of postdeposition heat-treatment on morphology and microstructure of CdTe grown by electrodeposition Electrochem. Soc. 143517

[20] Rounmagnac P, Guillemer-Neel C, Saanouni K and Clavel M 2000 Mechanical behavior and deformation mechanisms of $\mathrm{Ni}-\mathrm{Ti}$ shape memory alloys in tension Eur. Phys. J. Appl. Phys. 10109

[21] Gall K, Sehitoglu H, Chumlyakov Y I, Kireeva I V and Maier H J 1999 The influence of aging on critical transformation stress levels and martensite start temperature in TiNi. Part II: Discussion of experimental results Trans. ASME 12128 